\title{
Hypotension, lipodystrophy, and insulin resistance in generalized PPAR $\gamma$-deficient mice rescued from embryonic lethality
}

Sheng Zhong Duan, ${ }^{1}$ Christine Y. Ivashchenko, ${ }^{1}$ Steven E. Whitesall, ${ }^{1}$ Louis G. D'Alecy, ${ }^{1,2,3}$ Damon C. Duquaine, ${ }^{4}$ Frank C. Brosius III, ${ }^{1,4}$ Frank J. Gonzalez, ${ }^{5}$ Charles Vinson, ${ }^{5}$ Melissa A. Pierre, ${ }^{6}$ David S. Milstone, ${ }^{6}$ and Richard M. Mortensen ${ }^{1,7,8}$

\begin{abstract}
'Department of Molecular and Integrative Physiology and 'Department of Surgery, University of Michigan Medical School, Ann Arbor, Michigan, USA. ${ }^{3}$ Department of Surgery, William Beaumont Hospital, Royal Oak, Michigan, USA.

${ }^{4}$ Department of Internal Medicine, Nephrology Division, University of Michigan Medical School, Ann Arbor, Michigan, USA. ${ }^{5}$ Laboratory of Metabolism, National Cancer Institute, NIH, Bethesda, Maryland, USA. ${ }^{6}$ Vascular Research Division, Department of Pathology, Brigham and Women's Hospital, Harvard Medical School, Boston, Massachusetts, USA. ${ }^{7}$ Department of Pharmacology and ${ }^{8}$ Department of Internal Medicine, Metabolism, Endocrinology, and Diabetes Division, University of Michigan Medical School, Ann Arbor, Michigan, USA.
\end{abstract}

\begin{abstract}
We rescued the embryonic lethality of global PPAR $\gamma$ knockout by breeding Mox2-Cre (MORE) mice with floxed PPAR $\gamma$ mice to inactivate PPAR $\gamma$ in the embryo but not in trophoblasts and created a generalized PPAR $\gamma$ knockout mouse model, MORE-PPAR $\gamma$ knockout (MORE-PGKO) mice. PPAR $\gamma$ inactivation caused severe lipodystrophy and insulin resistance; surprisingly, it also caused hypotension. Paradoxically, PPAR $\gamma$ agonists had the same effect. We showed that another mouse model of lipodystrophy was hypertensive, ruling out the lipodystrophy as a cause. Further, high salt loading did not correct the hypotension in MORE-PGKO mice. In vitro studies showed that the vasculature from MORE-PGKO mice was more sensitive to endothelial-dependent relaxation caused by muscarinic stimulation, but was not associated with changes in eNOS expression or phosphorylation. In addition, vascular smooth muscle had impaired contraction in response to $\alpha$-adrenergic agents. The renin-angiotensin-aldosterone system was mildly activated, consistent with increased vascular capacitance or decreased volume. These effects are likely mechanisms contributing to the hypotension. Our results demonstrated that PPAR $\gamma$ is required to maintain normal adiposity and insulin sensitivity in adult mice. Surprisingly, genetic loss of PPAR $\gamma$ function, like activation by agonists, lowered blood pressure, likely through a mechanism involving increased vascular relaxation.
\end{abstract}

\section{Introduction}

The metabolic syndrome (MetS) is a cluster of metabolic abnormalities (including obesity, insulin resistance, and dyslipidemia) associated with type 2 diabetes, hypertension, and atherosclerosis. It is considered one of the most serious medical conditions, with increasing threats to public health in modern societies $(1,2)$. The nuclear transcription factor PPAR $\gamma$ is a candidate for mediating the interface of metabolic and cardiovascular diseases (3). PPAR $\gamma$ can affect most, if not all, aspects of the MetS. It is highly expressed in adipocytes and important in controlling adipogenesis as well as gene expression in these cells $(4,5)$. Results of genetic deficiency studies have shown that PPAR $\gamma$ is required for adipogenesis (6-8). The PPAR $\gamma$-agonist thiazolidinediones (TZDs) increase insulin sensitivity, lower blood glucose, decrease circulating free fatty acids and triglycerides, lower blood pressure, and reduce atherosclerosis in insulin-resistant patients and animal models $(1,3,9)$. However, the role of PPAR $\gamma$ in these TZD-induced effects is not completely understood. Dominant-negative muta-

Nonstandard abbreviations used: Agt, angiotensinogen; GTT, glucose tolerance test; ITT, insulin tolerance test; LC, littermate control; MetS, metabolic syndrome; MORE, Mox2-Cre; MORE-PGKO, MORE-PPAR $\gamma$ knockout; NEFA, nonesterified fatty acids; PRA, plasma renin activity; RAS, renin-angiotensin-aldosterone system; TZD, thiazolidinedione.

Conflict of interest: The authors have declared that no conflict of interest exists. Citation for this article: J. Clin. Invest. 117:812-822 (2007). doi:10.1172/JCI28859. tions of PPAR $\gamma$ (Pro467Leu and Val290Met) in humans are associated with insulin resistance, diabetes, and hypertension (10), whereas a similar mutation (Pro467Leu) in mice causes hypertension and fat redistribution but not insulin resistance or diabetes (11). The PPAR $\gamma$ Pro12Ala polymorphism in humans is associated with type 2 diabetes, insulin resistance, and obesity (12), while the Pro12Ala mutation of PPAR $\gamma 2$ in mice causes lipodystrophy and mild glucose intolerance (13).

In order to explore the physiologic importance of PPAR $\gamma$ in the MetS, recent studies using conditional knockout strategies in mice have revealed the roles of PPAR $\gamma$ in individual tissues. Adipocyte PPAR $\gamma$ is required for normal adiposity (14-16) and insulin sensitivity in fat and liver, but not in muscle (15). Myocyte PPAR $\gamma$ is required to maintain whole-body insulin sensitivity (17) or liver insulin sensitivity only (18). Hepatic PPAR $\gamma$ is required to maintain insulin sensitivity, particularly in older animals or in animals with genetically diabetic backgrounds $(19,20)$. Endothelial PPAR $\gamma$ is important in regulating dietinduced hypertension (21).

However, the effects of global deletion - including the multifaceted interaction PPAR $\gamma$ may have in multiple tissues - have not yet been addressed because of the lethality of the germline knockout of PPAR $\gamma(7,8)$. The MetS is a complex disease involving interactions among different tissues. In order to better understand the function of PPAR $\gamma$ in this disease, a generalized knock- 


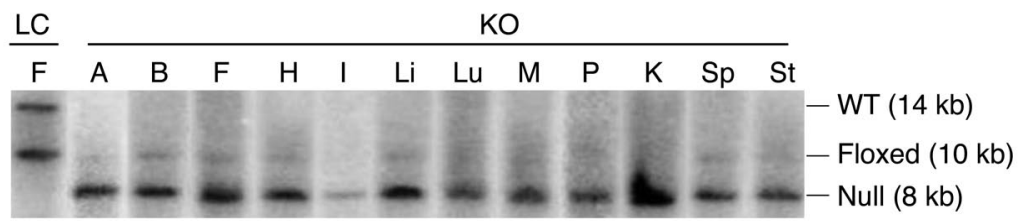

\section{Figure 1}

MORE-PGKO mice show extensive recombination. Representative Southern blot results of tissues from female LC and MORE-PGKO (KO) mice. The 14-kb endogenous WT allele appeared only in LC mice. The 8-kb Cre-recombined null allele appeared only in MORE-PGKO mice. The 10-kb floxed allele was rare in MORE-PGKO mice. A, aorta; B, brain; F, fat; H, heart; I, intestine; Li, liver; Lu, lung; M, skeletal muscle; $\mathrm{P}$, pancreas; K, kidney; Sp, spleen; St, stomach.

out model is necessary. The whole-body knockout of PPAR $\gamma 2$ (22) is mostly restricted to adipocytes (5). Here we describe a generalized PPAR $\gamma$-knockout (both PPAR $\gamma 1$ and PPAR $\gamma 2$ ) mouse model, Mox2-Cre-PPAR $\gamma$ knockout (MORE-PGKO), which rescues embryonic lethality by preserving PPAR $\gamma$ expression in the trophoblasts. Our data showed that global PPAR $\gamma$ deficiency caused lipodystrophy and insulin resistance, which was surprisingly accompanied by lower blood pressure. In contrast, A-ZIP mice, which expressed a dominant negative protein A-ZIP/F that caused lipodystrophy (23), were hypertensive, establishing them as a model of lipodystrophic hypertension comparable to that seen in humans. Thus, both genetic loss of PPAR $\gamma$ function and activation by pharmacologic agonist had similar effects on blood pressure.

\section{Results}

The MORE-PGKO mouse model. MORE-PGKO mice were born in the expected Mendelian ratio, but only approximately $10 \%$ survived to adulthood. In MORE mice, Cre recombinase is uniformly expressed in epiblast-derived tissue, but not other tissues (24), thus sparing trophoblast. Southern blot analysis revealed an $8-\mathrm{kb}$ restriction fragment representing the $\operatorname{PAAR} \gamma$-null allele, which indicated successful Cre-mediated recombination (6), in multiple tissues of MORE-PGKO mice (Figure 1). Tissues from littermate control (LC) mice revealed 14 - and $10-\mathrm{kb}$ restriction fragments representing WT and floxed PPAR $\gamma$ alleles, respectively (6), which indicated lack of recombination. Among all tissues tested in MORE-PGKO mice, approximately $94.5 \% \pm 4.3 \%$ and $95.4 \% \pm 6 \%$ of the floxed PPAR $\gamma$ allele was recombined to the null allele in females and males, respectively.

Generalized PPAR $\gamma$ deficiency causes lipodystrophy and organomegaly. PPAR $\gamma$ has previously been shown to regulate adipocyte differentiation in vitro $(6,7)$, and mice with adipocyte-specific PPAR $\gamma$ deficiency have less adipose tissue than do WT controls, although a substantial amount of adipose tissue remains $(14,15)$. Furthermore, PPAR $\gamma$ is required for adipocyte survival in adult mice (16). MORE-PGKO mice, in contrast, showed more severe lipodystrophy (Figure 2). Dual-energy x-ray absorptiometry (DEXA) scan showed that MORE-PGKO mice had dramatically less fat mass than did LC mice at 6 months of age (Figure 2A). Both male and female MORE-PGKO mice lacked interscapular brown adipose tissue as well as mesenteric, perirenal, and subcutaneous fat (Figure 2, B-D, and data not shown). Epididymal fat and periovarian fat was also absent in male and female MORE-PGKO mice, respectively (Figure 2, B and C). However, female MORE-PGKO mice had a small amount of periuterine fat, approximately 9\% that of LC mice (Figure 2, B and C). Quantitative RT-PCR showed that PPAR $\gamma$ was expressed, albeit at very low level, in the periuterine fat of female MORE-PGKO mice (Figure 2E), indicating at least partial escape from Cre-loxP-mediated recombination in this depot.

In spite of this lipodystrophy, body weight and length were comparable in MORE-PGKO and LC mice (Table 1). The adrenal gland, kidney, liver, lung, pancreas, thyroid, and heart weights of MORE-PGKO mice were all significantly greater than those of LC mice (Table 1). This organomegaly was similar to that seen in A-ZIP mice, another lipodystrophic mouse model (23).

Insulin resistance in MORE-PGKO mice. Previous studies using tissue-specific knockout strategies have demonstrated that adipocyte, myocyte, and hepatocyte PPAR $\gamma$ all play important roles in maintaining insulin sensitivity and glucose homeostasis (15, 17-20). We evaluated insulin sensitivity and glucose homeostasis in MORE-PGKO and LC mice at 6 months of age. Insulin tolerance test (ITT) showed that both male and female MORE-PGKO mice had impaired insulin sensitivity compared with LC mice (Figure 3, $A$ and D). They had significantly elevated fed plasma insulin levels (Figure 3, B and E), also demonstrating insulin resistance. Histologic analysis revealed enlarged pancreatic islets in MORE-PGKO mice (Figure 3, C and F). Male MORE-PGKO mice were diabetic, with impaired glucose tolerance test (GTT; Figure 4A) and elevated fed blood glucose (Figure 4B). However, female MORE-PGKO mice were not diabetic (Figure 4E) and showed enhanced glucose tolerance (Figure 4D) compared with LC mice, probably because of higher plasma insulin levels after overnight food deprivation and during GTT in female MORE-PGKO mice (Figure 4F). Conversely, male MORE-PGKO mice showed

\section{Table 1}

Body weight and length and organ weights of 6-month-old male mice

\begin{tabular}{lccc}
\hline & & & \\
& LC & MORE-PGKO & $\boldsymbol{P}$ \\
Body weight $(\mathrm{g})$ & $34.5 \pm 5.0$ & $34.8 \pm 4.0$ & 0.45 \\
Body length $(\mathrm{mm})$ & $91.0 \pm 6.2$ & $93.3 \pm 7.6$ & 0.32 \\
Adrenal gland $(\mathrm{mg} / \mathrm{g})$ & $0.14 \pm 0.03$ & $0.20 \pm 0.03$ & 0.027 \\
Kidney $(\mathrm{mg} / \mathrm{g})$ & $16.2 \pm 0.7$ & $18.3 \pm 0.4$ & 0.0056 \\
Liver $(\mathrm{mg} / \mathrm{g})$ & $49.4 \pm 6.6$ & $69.7 \pm 18$ & 0.0012 \\
Lung $(\mathrm{mg} / \mathrm{g})$ & $5.3 \pm 0.5$ & $6.1 \pm 0.4$ & 0.017 \\
Pancreas $(\mathrm{mg} / \mathrm{g})$ & $11.7 \pm 1.4$ & $14.8 \pm 1.8$ & 0.0023 \\
Thyroid $(\mathrm{mg} / \mathrm{g})$ & $0.07 \pm 0.01$ & $0.12 \pm 0.04$ & 0.012 \\
Heart $(\mathrm{mg} / \mathrm{g})$ & $3.9 \pm 0.2$ & $4.3 \pm 0.2$ & 0.017 \\
\hline
\end{tabular}

Individual organ weights are expressed relative to body weight. Results were similar for female mice. $n=8-11$ per group. 
A

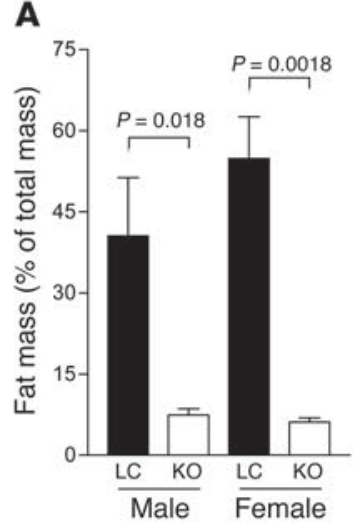

C

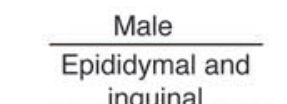
inguinal

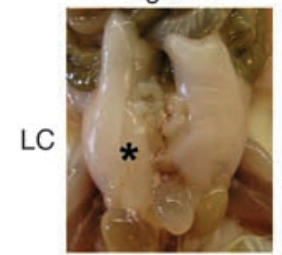

KO

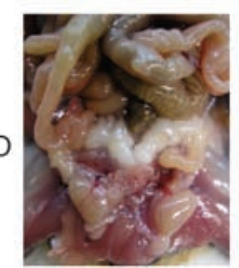

D
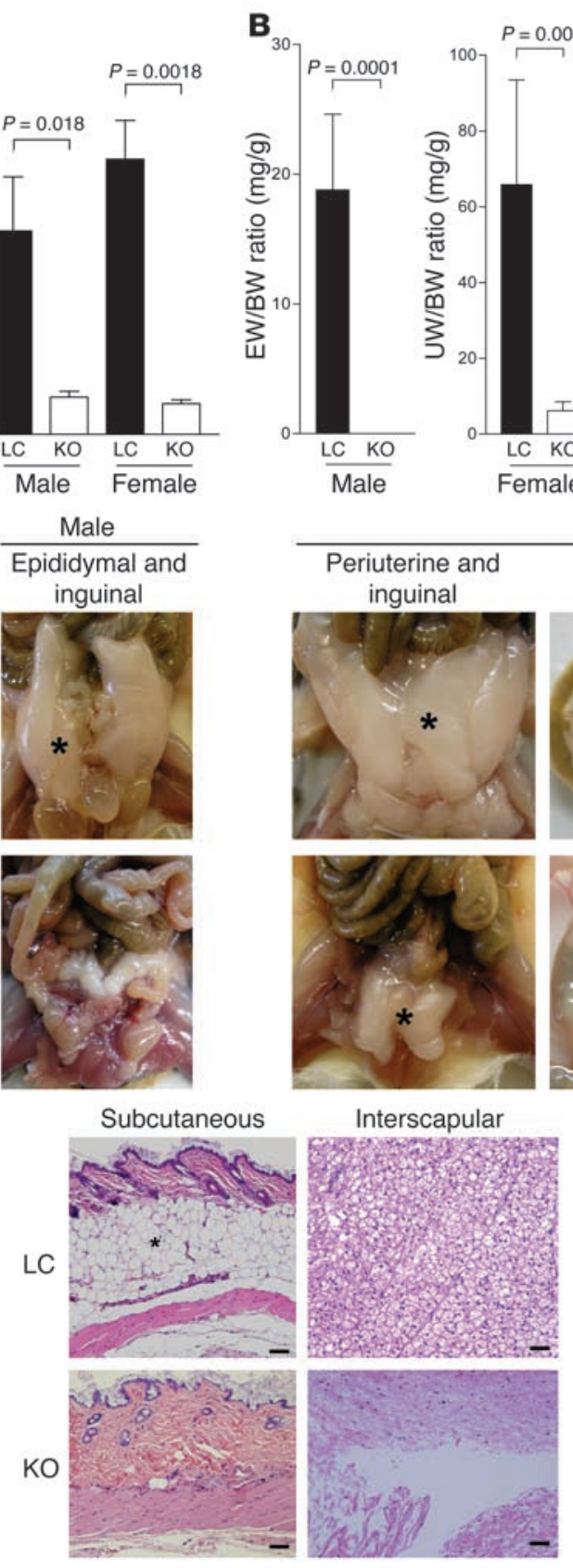
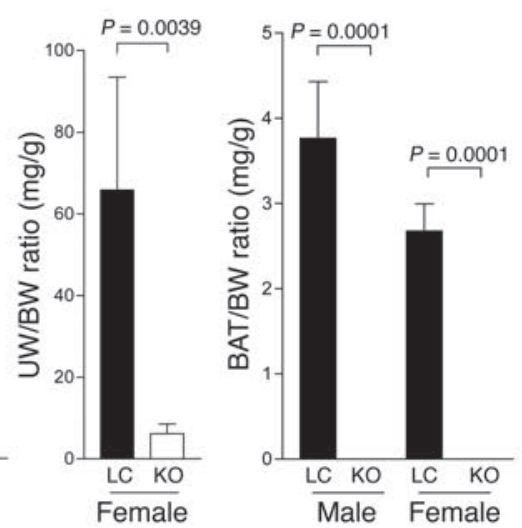

Female
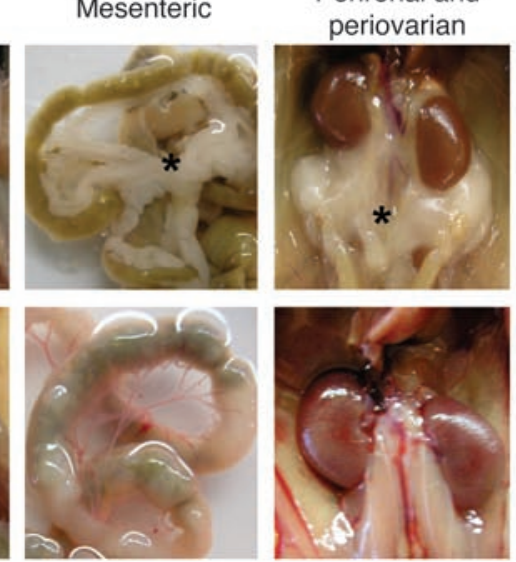

\section{Inter- scapular}
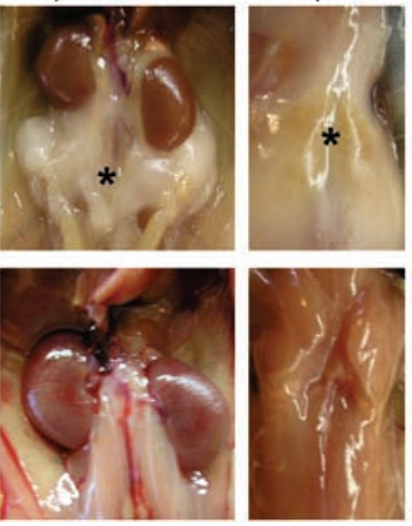

E

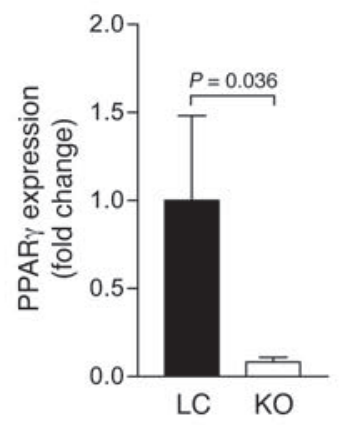

\section{Figure 2}

Lipodystrophy in MORE-PGKO mice. (A) Dual-energy x-ray absorptiometry (DEXA) scan showed significantly decreased fat mass in MOREPGKO mice. $n=8-11$ for each gender and genotype. (B) Fat pad weight to body weight (BW) ratios. EW, epididymal fat; UW, periuterine fat; BAT, interscapular brown adipose tissue. $n=8-11$ for each gender and genotype. Epididymal fat in male MORE-PGKO mice and interscapular brown adipose tissue in both male and female MORE-PGKO mice were measured as 0 for all animals in the group. (C) Representative gross photographs of fat pads (indicated by asterisks). (D) Representative H\&E histology of fat depots from female mice. Asterisk denotes the subcutaneous fat layer. Scale bars: $100 \mu \mathrm{m}$. (E) Quantitative RT-PCR of PPAR $\gamma$ expression in periuterine fat of female mice. $\beta$-Actin was used as an endogenous control. $n=4$ per group.

significantly lower plasma insulin levels than did LC mice during GTT (Figure 4C).

Both male and female MORE-PGKO mice had significantly decreased plasma leptin and adiponectin levels (Figure 5 , A and B) as well as elevated plasma nonesterified fatty acids (NEFAs) and triglycerides (Figure 5, C and D) compared with LC mice, which can contribute to insulin resistance. Although adipose-specific and skeletal muscle-specific PPAR $\gamma$ knockout mice both displayed fatty liver as well as insulin resistance $(15,17)$, the livers of MORE-PGKO mice were histologically similar to those of LC mice, without apparent lipid accumulation, hepatocellular damage, or inflammation (Figure 6). This is consistent with previ- 
A

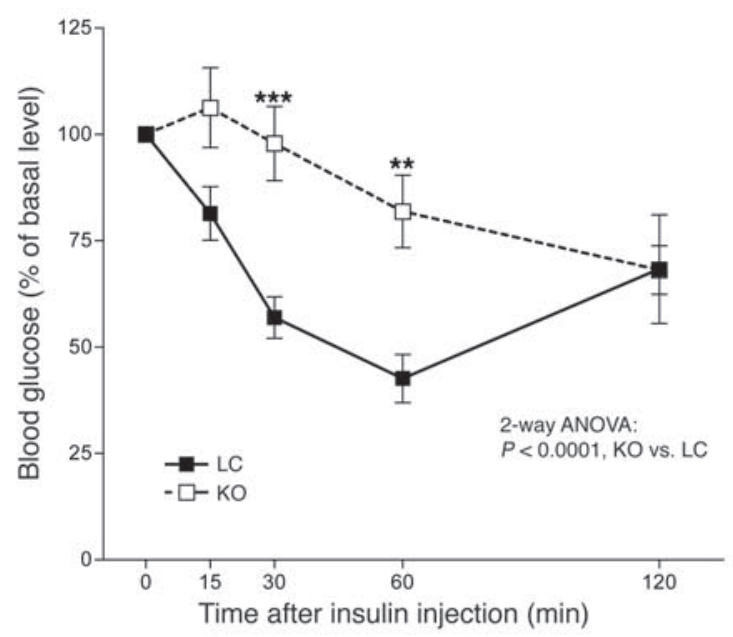

D

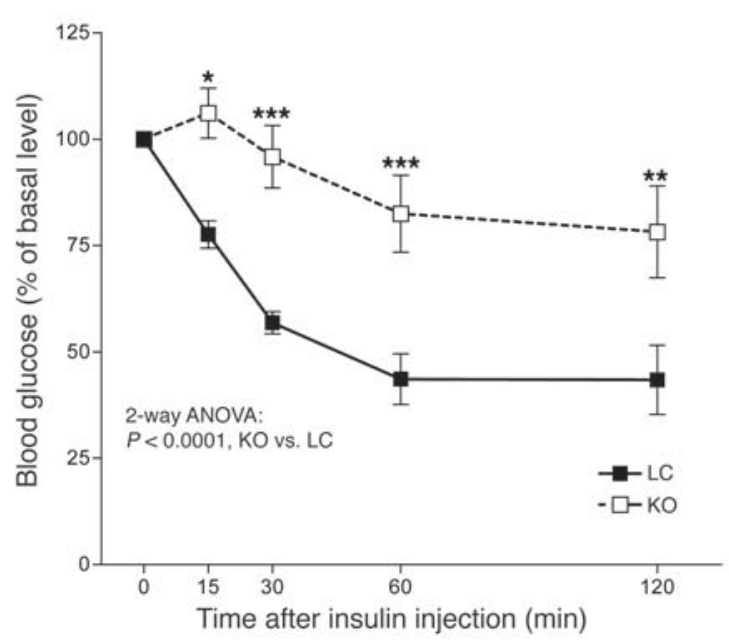

B

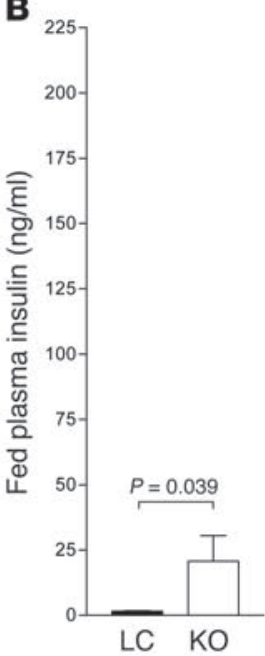

E

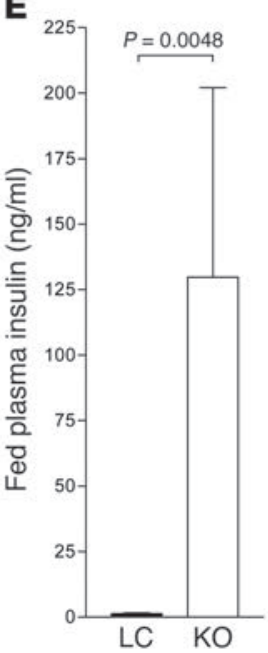

C
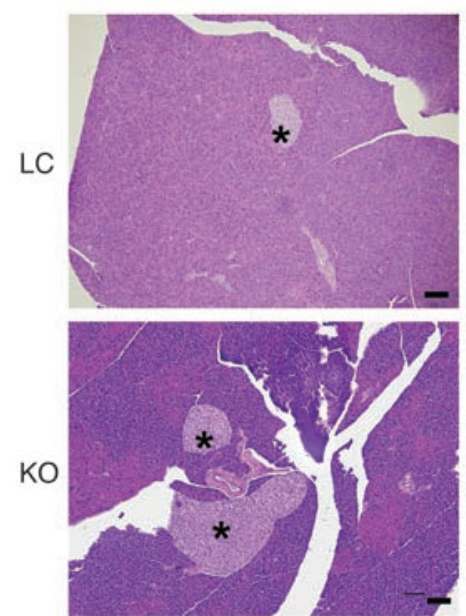

$\mathbf{F}$

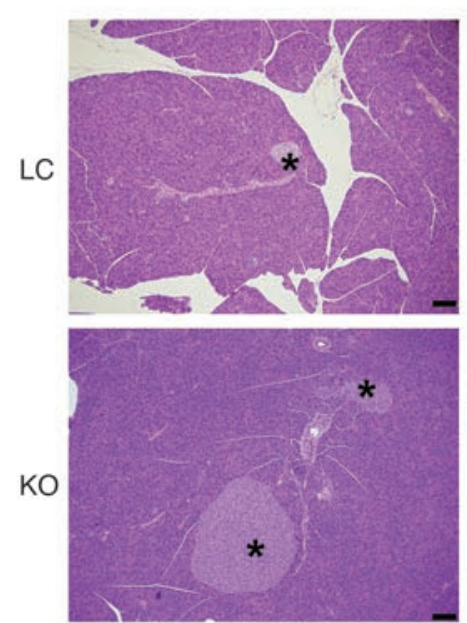

Figure 3

Insulin resistance in male and female MORE-PGKO mice. $n=8-11$ per group. ITT (A and D), fed plasma insulin levels (B and E), and representative H\&E histology (C and F) in male (A-C) and female (D-F) MORE-PGKO and LC mice. Male MORE-PGKO mice showed significantly impaired insulin sensitivity and significantly higher insulin levels, and enlarged islets in male MORE-PGKO mice were apparent (indicated by asterisks). Results in females were similar to those in males, except plasma insulin levels were higher in female MORE-PGKO mice. ${ }^{\star} P<0.05$, ${ }^{* \star} P<0.01,{ }^{* *} P<0.001$ versus LC, Bonferroni post-test. Scale bars: $100 \mu \mathrm{m}$.

ous data showing that liver-specific PPAR $\gamma$ deficiency protects against hepatic steatosis in leptin-deficient mice and lipodystrophic A-ZIP mice $(19,20)$.

Hypotension in MORE-PGKO mice. Dominant-negative mutations of PPAR $\gamma$ cause hypertension, a cardinal characteristic of the MetS $(1,2)$, in both humans and mice $(10,11)$. TZDs also decrease blood pressure in insulin-resistant patients and animal models (25-27). We therefore sought to determine the consequences of PPAR $\gamma$ deficiency on blood pressure regulation. Blood pressure and heart rate were monitored by radiotelemetry. Surprisingly, despite severe insulin resistance, both systolic and diastolic blood pressure of MORE-PGKO mice were significantly lower than those of LC mice (Figure 7, A and B). In addition, the heart rates of MORE-PGKO mice were significantly higher than those of LC mice (Figure 7C).
Dietary salt loading caused small, nearly identical blood pressure increases in both MORE-PGKO and LC mice (Figure 8) that were consistent with previously reported changes in WT mice (28). Compared with LC mice, MORE-PGKO mice remained hypotensive with a high-salt diet (Figure 8). Salt loading did not significantly change heart rate in either genotype (data not shown). Food consumption (both normal and high-salt diets) was not significantly different between MORE-PGKO and LC mice.

In order to determine whether hypotension was caused by impaired vasoactivity, we tested the responses of aortic rings to graded levels of phenylephrine and acetylcholine. Aortic rings from MORE-PGKO mice showed significantly lower maximum contraction in response to phenylephrine than did rings from LC mice (Figure 9A), although $-\log \left[\mathrm{EC}_{50}\right]$ values were not significantly different between groups (LC, $7.46 \pm 0.26$; MORE-PGKO, 

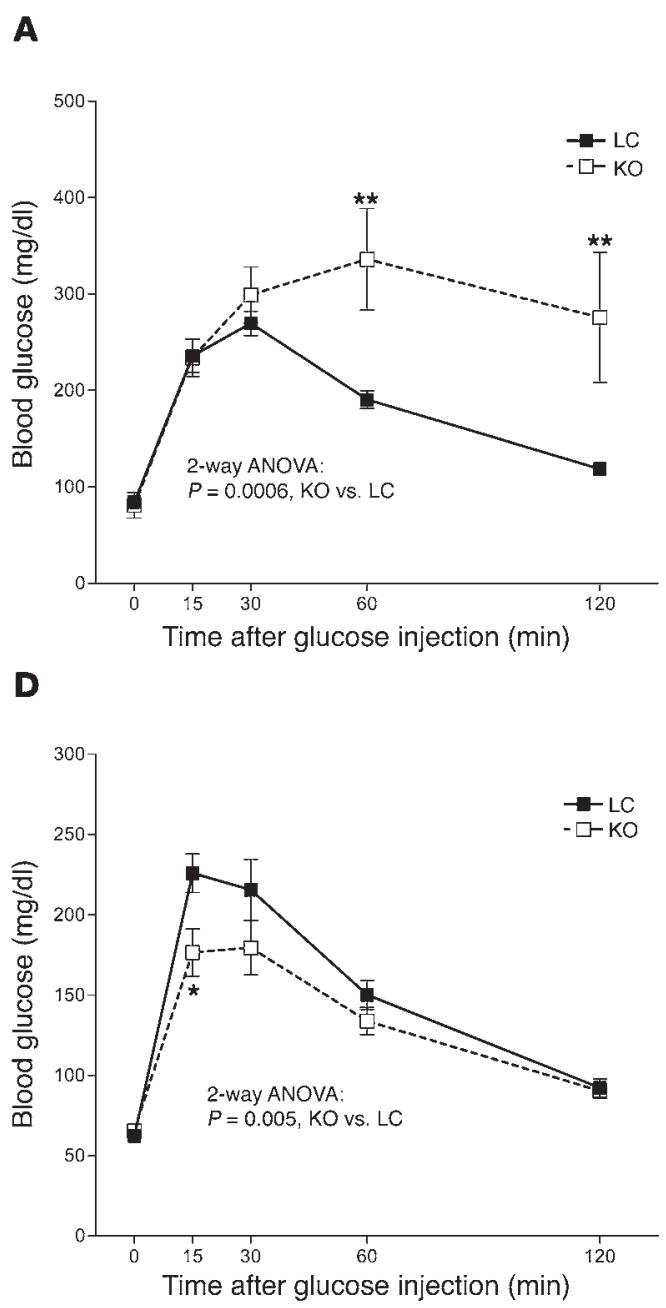
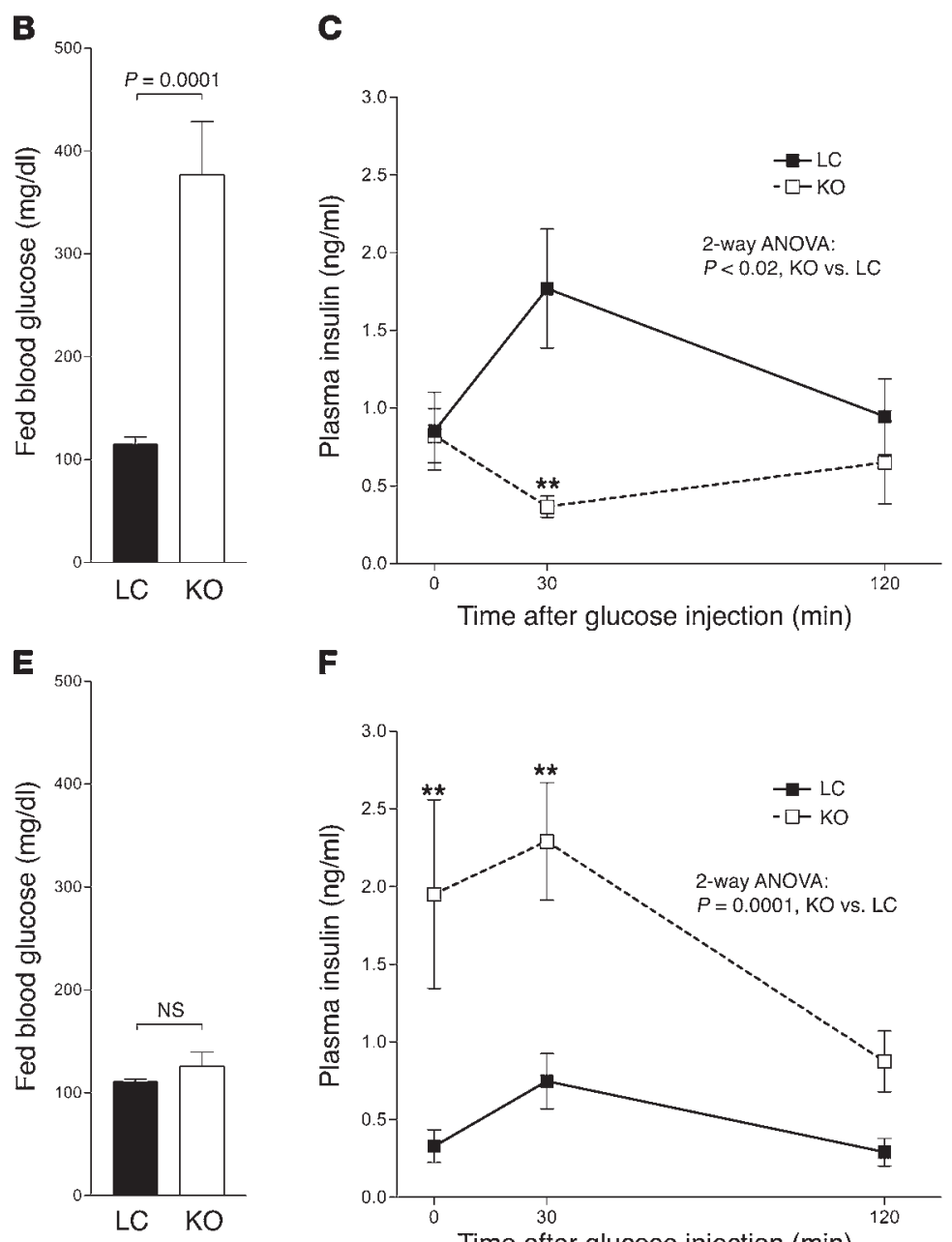

$\mathbf{F}$

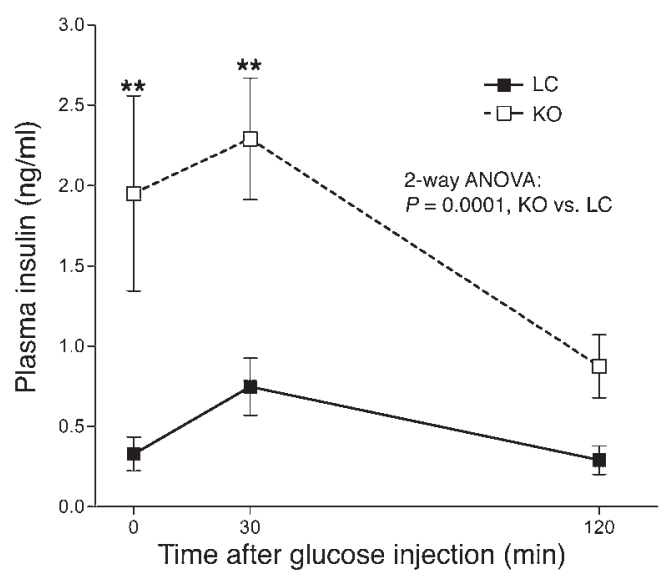

Figure 4

Gender dimorphism of glucose tolerance in MORE-PGKO mice. $n=8-11$ per group. GTT (A and D), blood glucose levels (B and E), and plasma insulin levels (C and $\mathbf{F})$ in male (A-C) and female (D-F) MORE-PGKO and LC mice. Male MORE-PGKO mice showed significantly impaired glucose tolerance compared with LC mice, were diabetic, and showed lower plasma insulin levels than did LC mice during GTT. Female MORE-PGKO mice were more tolerant of glucose than were LC mice. Blood glucose levels were comparable in female MOREPGKO and LC mice. Higher plasma insulin levels were observed in female MORE-PGKO mice than in LC mice during GTT. ${ }^{\star} P<0.05$, ${ }^{* \star} P<0.01$ versus LC, Bonferroni post-test.

$7.25 \pm 0.93 ; P=0.29)$. This suggests decreased vascular smooth muscle contractility in MORE-PGKO mice. In addition, the doseresponse curve for MORE-PGKO mouse aortic rings responding to acetylcholine significantly shifted to the left compared with the curve for LC mice $\left(-\log \left[\mathrm{EC}_{50}\right], \mathrm{LC}, 7.97 \pm 0.16\right.$; MORE-PGKO, $8.32 \pm 0.42 ; P=0.024$; Figure 9B), indicating that MORE-PGKO mouse aortas are more sensitive to relaxation by acetylcholine than are those of LC mice.

Overexpression of eNOS results in hypotension (29), and the PPAR $\gamma$ agonist rosiglitazone increases NO production in cultured endothelial cells (potentially by increasing eNOS activity), reflected by increased phosphorylation of eNOS at Ser 1177 (30). In order to determine whether eNOS contributes to the hypotension phenotype, we examined its expression and phosphorylation (Ser1177) in aortas from MORE-PGKO and LC mice. The mRNA and protein phosphorylation levels of eNOS were not significantly different between MORE-PGKO and
LC mice (Figure 10). MORE-PGKO mouse aortas had normal histology and expression of macrophage marker F4/80 compared with that of LC mice (Supplemental Figure 1; supplemental material available online with this article; doi:10.1172/ JCI28859DS1).

Renin-angiotensin-aldosterone system (RAS) is important in blood pressure regulation and vascular volume control (31). Renal collecting duct-specific PPAR $\gamma$ knockout mice have either elevated (32) or normal plasma aldosterone levels (33). Both plasma aldosterone levels and plasma renin activity (PRA) were increased in MORE-PGKO mice compared with LC mice (Figure 11, $A$ and $B$ ). However, the RAS gene expression, including that of angiotensinogen (Agt) and renin, was not changed in kidney, liver, or fat (Figure 11, C-E).

Although lipodystrophy is associated with hypertension in humans $(34,35)$, to our knowledge, this association has not previously been tested in mice. We therefore measured blood pressure 
A

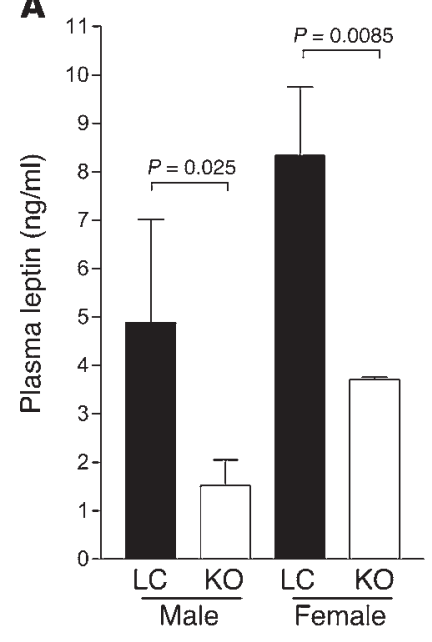

B

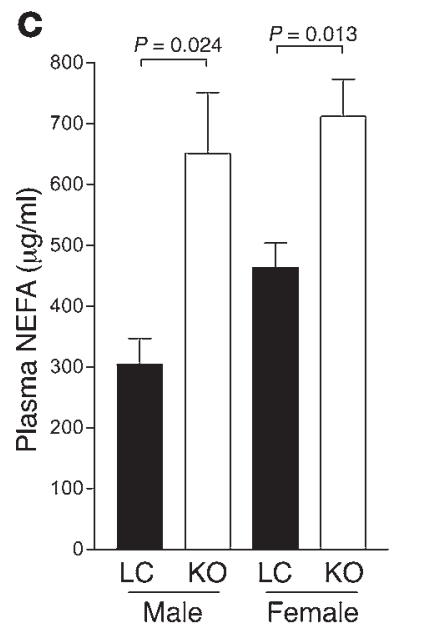

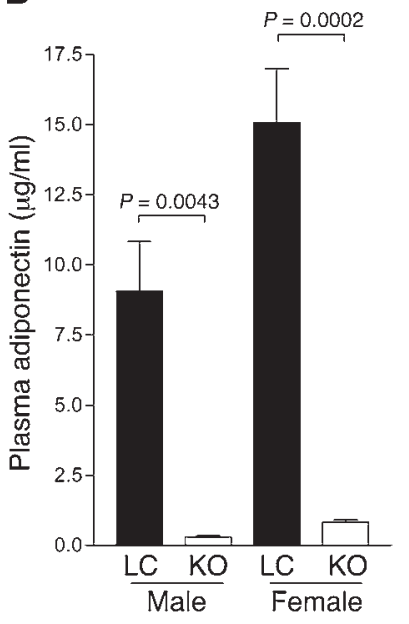

D $P=0.025$

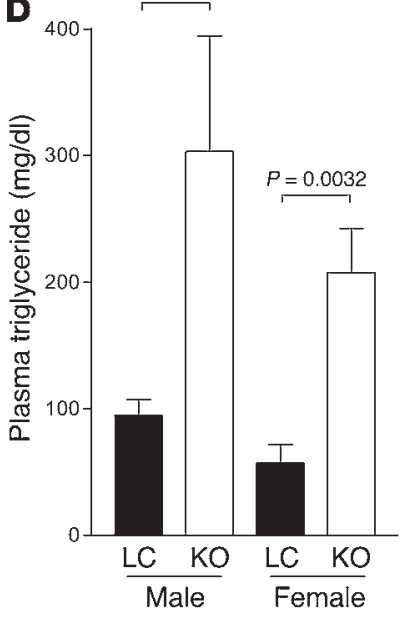

in A-ZIP mice (23), another lipodystrophic model. A-ZIP mice had higher systolic and diastolic blood pressure and lower heart rate than did WT mice (Figure 12), indicating that hypotension in MORE-PGKO mice is not attributable to lipodystrophy.

\section{Discussion}

Recent in vivo studies using conditional knockout mouse models have established the importance of PPAR $\gamma$ in different aspects of the MetS (14-21). However, when investigating the mechanisms of diseases involving multiple organs, a cell type-specific approach may not be sufficient. Here we developed and studied a global knockout mouse model of PPAR $\gamma$ (both PPAR $\gamma 1$ and PPAR $\gamma 2$ ), MORE-PGKO mice, in order to understand the integrative roles of PPAR $y$ in the complex of MetS.

MORE-PGKO mice had severe lipodystrophy, which further supports the regulatory role of PPAR $\gamma$ in adiposity in vivo. Female MORE-PGKO mice had a small amount of periuterine fat, but male MORE-PGKO mice had no detectable fat depots. This probably reflects escape from Cre-loxP-mediated recombination in the periuterine fat of female MORE-PGKO mice, although recombination was similar in other tissues from males and females. Another possibility is that this is related to effects of estrogen on growth of specific adipose depots (36). Organomegaly in MORE-PGKO mice was similar to that previously reported

\section{Figure 5}

Low adipokines and hyperlipidemia in MORE-PGKO mice. $n=8-11$ for each gender and genotype. Both male and female MORE-PGKO mice showed significantly lower plasma leptin (A) and adiponectin (B) levels and significantly higher plasma NEFA (C) and triglyceride (D) levels than did LC mice.

in lipodystrophic A-ZIP mice (23), suggesting a link between organomegaly and lipodystrophy. However, we have previously shown that a lack of PPAR $\gamma$ specifically in cardiomyocytes results in cardiac hypertrophy without lipodystrophy (37). In addition, PPAR $\gamma$ deficiency specifically in pancreatic islets causes islet hyperplasia (38). Furthermore, PPAR $\gamma$ agonists can inhibit proliferation of vascular and airway smooth muscle cells $(39,40)$, bile ducts (41), and kidney fibroblasts (42) as well as a variety of cancer cells in vitro and/or in vivo $(43,44)$. These findings suggest that PPAR $\gamma$ can act as an intrinsic growth inhibitor and that generalized PPAR $\gamma$ deficiency might cause generalized organomegaly independent of lipodystrophy. However, whether PPAR $\gamma$ plays a similar growth-inhibitory role in organs other than the heart and pancreas remains to be determined.

The severe insulin resistance we observed in MORE-PGKO mice demonstrated that PPAR $\gamma$ is a key regulator of insulin sensitivity. However, insulin resistance and glucose intolerance are not always associated (13). Male, but not female, MORE-PGKO mice were diabetic. In fact, female MORE-PGKO mice showed greater glucose tolerance than did female LC mice, likely because of much higher plasma insulin levels and changes with fasting during GTT. In addition, MORE-PGKO mice lacked hepatic steatosis, another feature observed in mice with insulin resistance, including mice with adipose-specific and musclespecific PPAR $\gamma$ deficiency $(15,17)$. This probably reflects the protective effect of hepatic PPAR $\gamma$ deficiency that has been previously shown to improve hepatic steatosis in leptin-deficient $(o b / o b)$ mice (19) and lipodystrophic A-ZIP mice (20), both of which are insulin resistant.

Lipodystrophy and insulin resistance are both associated with hypertension, another component of the MetS, in humans (34, 35). Our results demonstrated the association of hypertension, lipodystrophy, and insulin resistance in A-ZIP mice. Intriguingly, the MORE-PGKO mice were lipodystrophic and insulin resistant but hypotensive, suggesting that hypertension is

\section{A}

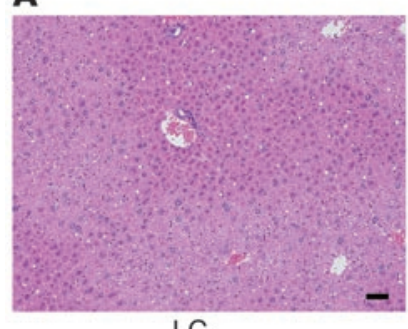

LC

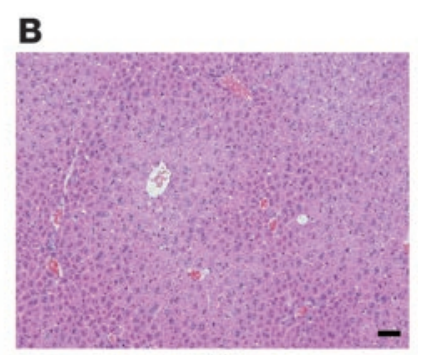

$\mathrm{KO}$

\section{Figure 6}

Normal liver histology in MORE-PGKO mice. Representative H\&E histology of liver from male LC (A) and MORE-PGKO (B) mice. Results were similar for female MORE-PGKO and LC mice. Scale bars: $100 \mu \mathrm{m}$. 

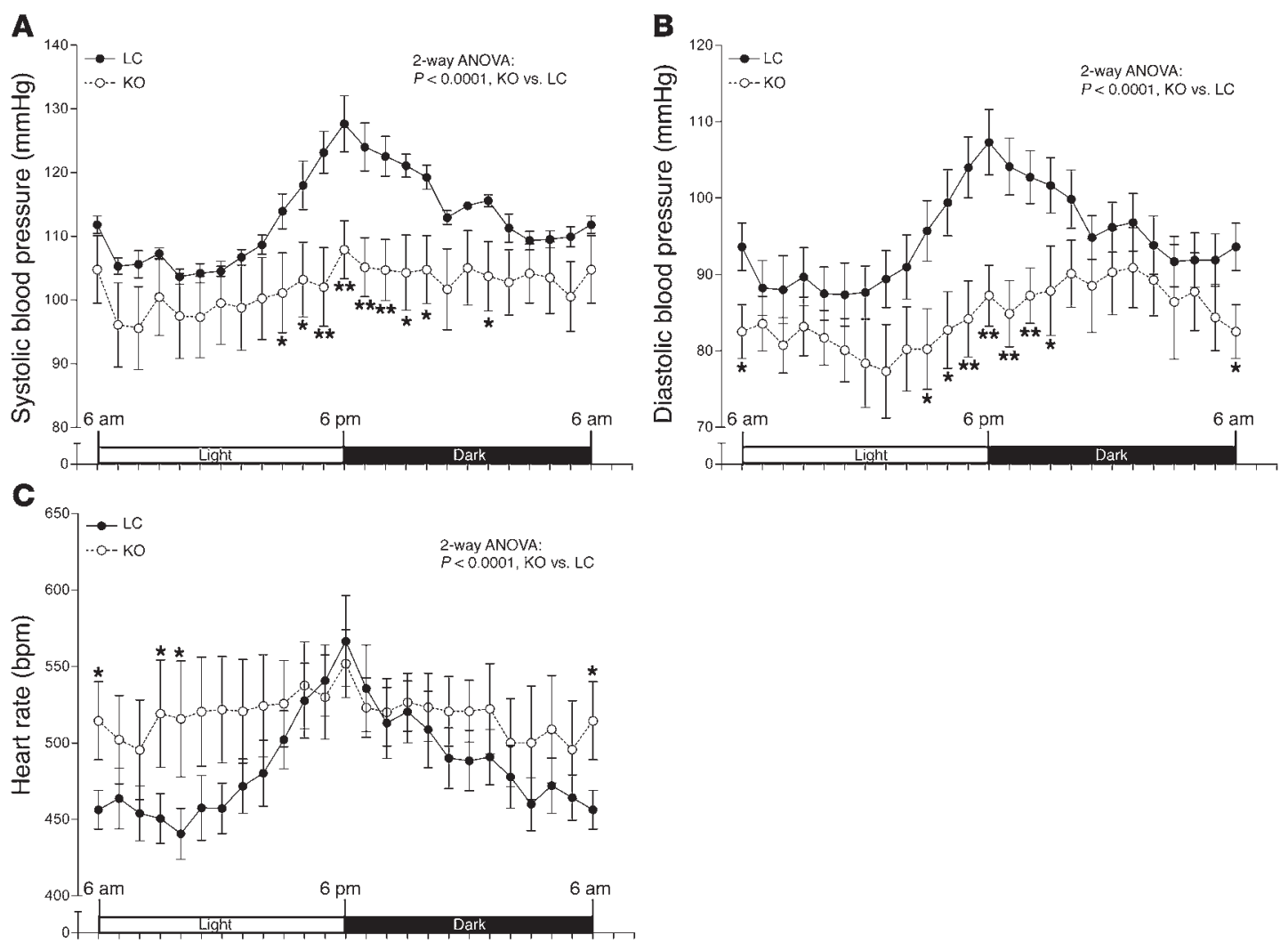

Figure 7

Hypotension in MORE-PGKO mice. Systolic (A) and diastolic (B) blood pressure and heart rate (C) of MORE-PGKO and LC mice. MORE-PGKO mice showed significantly lower systolic and diastolic pressure and higher heart rates than did LC mice. Results were similar in both genders and were combined ( $n=8,4$ males and 4 females, for each genotype). Data collected over 2 weeks were averaged and presented as light/dark cycle over a 24 -hour period. ${ }^{*} P<0.05,{ }^{*} P<0.01$ versus LC, Bonferroni post-test.

separable from lipodystrophy or insulin resistance. Paradoxically, the PPAR $\gamma$-agonist TZDs have previously been shown to decrease blood pressure (25-27). Knockout phenotypes that mimic agonist phenotypes suggest that blood pressure control by PPAR $\gamma$ is likely mediated by gene suppression that both agonist and genetic deficiency are capable of relieving. The phenomenon that deletion of PPAR $\gamma$ as well as its agonists have similar effects resembles the previous finding that pioglitazone, a TZD, and PPAR $\gamma$ knockout both increase sodium absorption in cultured inner medullary collecting ducts (32). Another example is the effects of PPAR $\delta$, another member of the PPAR family, in atherogenic inflammation: inactivation of PPAR $\delta$ as well as its agonist has an antiinflammatory effect by dissociating PPAR $\delta$ from transcriptional repressor BCL-6 (45).

It is unlikely that the hypotension in MORE-PGKO mice is because of lower sympathetic drive caused by lower plasma leptin levels (46) because their heart rates were significantly higher than those of LC mice. Both aldosterone levels and PRA were mildly elevated in the plasma of MORE-PGKO mice, indicating activation of the RAS. The failure of salt loading to correct the hypotension in MORE-PGKO mice suggests that a simple lack of salt retention is not responsible for the phenotype, consistent with the normal blood pressure observed in collecting duct-specific PPAR $\gamma$ knockout mice (33). Therefore, increased vasorelaxation and decreased vasoconstriction are likely signifi- cant contributors to the hypotension, although a combination with mild renal effects cannot be ruled out.

Baseline blood pressure is normal in mice with endothelial cellrestricted PPAR $\gamma$ deficiency (21), although a different method was used to measure blood pressure than the one used in the current study. It is likely that PPAR $\gamma$ in other cell types, such as vascular smooth muscle cells, are more important in mediating the effect of PPAR $\gamma$ on blood pressure regulation. Further investigation of mice with smooth muscle cell-specific PPAR $\gamma$ deficiency would help clarify this situation.

eNOS is an important regulator of blood pressure and vascular reactivity (29), but changes in expression or phosphorylation were not found in MORE-PGKO aortas. The involvement of macrophages in the vasculature of MORE-PGKO mice is also unlikely to contribute to the hypotension phenotype, because no differences were found.

In summary, we demonstrated that allowing PPAR $\gamma$ expression in trophoblasts was sufficient to rescue embryonic lethality and confirmed that PPAR $\gamma$ was necessary for adipogenesis and normal insulin sensitivity in mice. Surprisingly, PPAR $\gamma$ deficiency caused increased vascular relaxation and decreased contraction, contributing to hypotension rather than the expected hypertension associated with lipodystrophy. The MORE-PGKO mouse model will provide a useful tool for further investigating the extent to which PPAR $\gamma$ mediates the effects of TZDs in the MetS. 

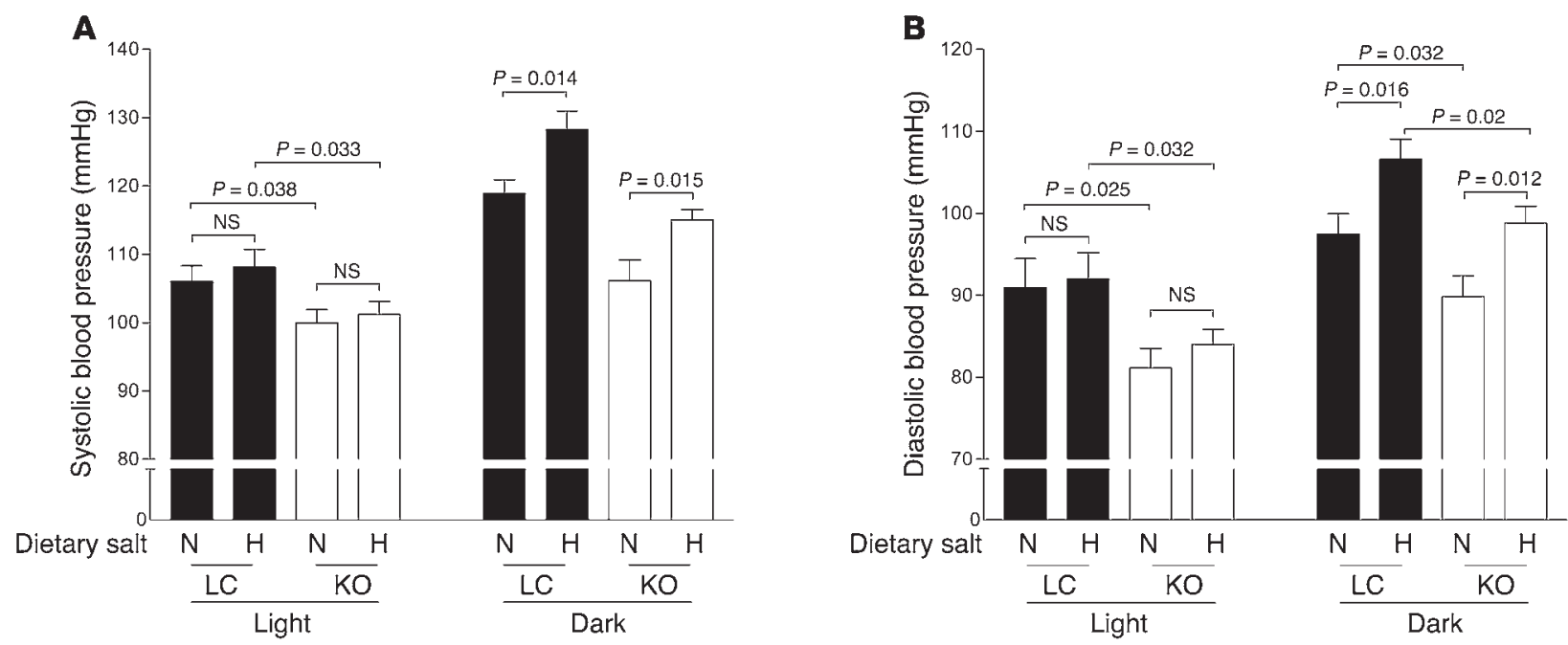

Figure 8

High-salt diet increases blood pressure in both MORE-PGKO and LC mice. $n=5$ per group. Mean systolic (A) and diastolic (B) blood pressure of male LC and MORE-PGKO mice on chow with normal $(\mathrm{N})$ or high $(\mathrm{H})$ dietary salt during light and dark cycles.

Our results also establish A-ZIP mice as a model of hypertensive lipodystrophy similar to that of humans.

\section{Methods}

Materials. Reagents were purchased from Sigma-Aldrich unless otherwise specified.

Animals. In MORE mice (24), Cre recombinase is expressed and enzymatically active in the germline. In order to obtain appropriate WT LC mice, MORE mice were first bred to floxed PPAR $\gamma$ mice (47) to obtain heterozygous PPAR $\gamma$ mice (floxed PPAR $\gamma / \mathrm{WT}$, MORE-positive/WT; designated PPAR $\gamma^{F / W T}: M O R E^{C r e / W T}$ and are functionally PPAR $\gamma^{-/ W T}: M O R E^{C r e} / W T$ in the germline), which were further bred to homozygous floxed PPAR $\gamma$ mice to generate both MORE-PGKO mice (floxed PPAR $\gamma /$ null, MORE-positive/WT; designated PPAR $\left.\gamma^{F /-}: M O R E^{C r e / W T}\right)$ and LC mice (PPAR $\left.\gamma^{F / W T}: M O R E^{W T / W T}\right)$. These mice were on a mixed C57BL/6, NIH Swiss, and 129SvEv background. A-ZIP lipodystrophic mice on FVB/N background were produced as described previously (23). All animal protocols were approved by the University Committee on Use and Care of Animals of the University of Michigan and by the Standing Committee On Animals of Harvard Medical School.

A

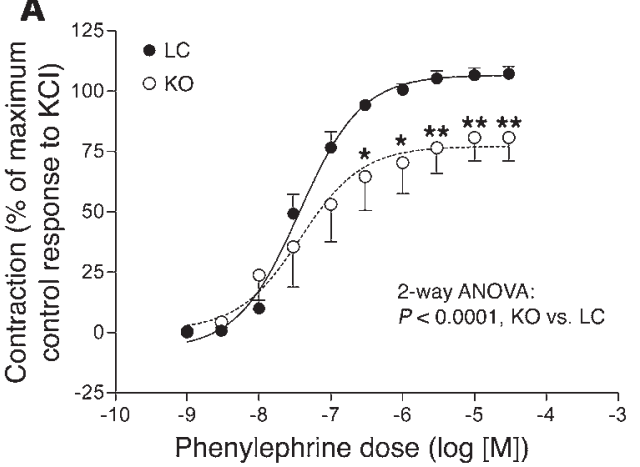

Southern blot. Genomic DNA was isolated from various tissues of MORE-PGKO and LC mice, digested with BamHI, separated by electrophoresis, transferred to nylon membrane, and hybridized with a ${ }^{32} \mathrm{P}$-labled DNA probe derived from the murine PPAR $\gamma$ gene ( 3 '-probe) as described previously $(37,47)$.

Fat mass estimation. DEXA (Norland Medical Systems Inc.) scanning was used to evaluate the ratio of fat mass to total mass in 6-month-old MORE-PGKO and LC mice $(n=8-11$ for separate male and female groups of each genotype). Macroscopic and histologic analyses of adipose tissue were performed to visualize fat mass. Epididymal fat pads, periuterine fat pads, and interscapular brown adipose tissue were weighed. The ratios of these fat pat weights to body weight were calculated.

Histologic analysis. Tissues were fixed in $10 \%$ neutral buffered formalin overnight and embedded in paraffin. Sections $(5 \mu \mathrm{m})$ were stained with H\&E. Digital images were obtained using an Olympus BX51 microscope (Olympus).

Gene expression analysis. The following genes were assayed using quantitative RT-PCR as described previously (48): PPAR $\gamma$, eNOS, renin, Agt, and $\beta$-actin. All primer-probe sets were purchased from Applied Biosystems.

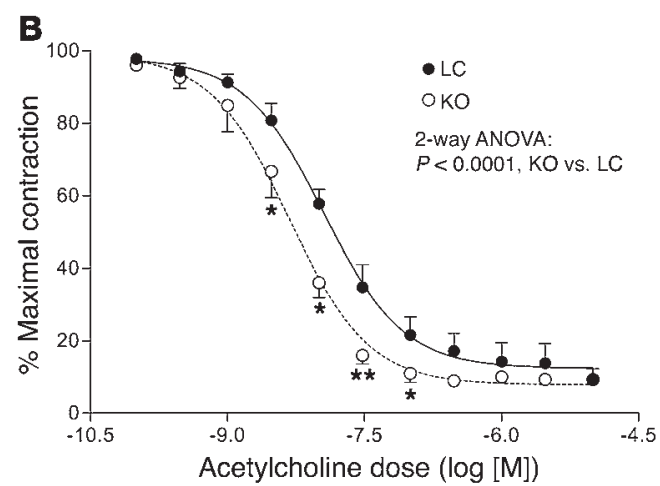

Figure 9

MORE-PGKO mice show impaired vasoactivity. Phenylephrine $(\mathbf{A})$ and acetylcholine $(\mathbf{B})$ dose-response curves of aortic rings from MORE-PGKO and LC mice. Results were similar in both genders and were combined ( $n=8,4$ males and 4 females, for each genotype). ${ }^{\star} P<0.05,{ }^{*} P<0.01$ versus LC, Bonferroni post-test. 


\section{A

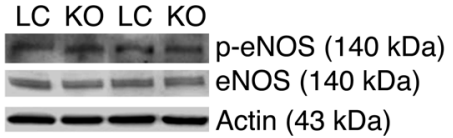

B
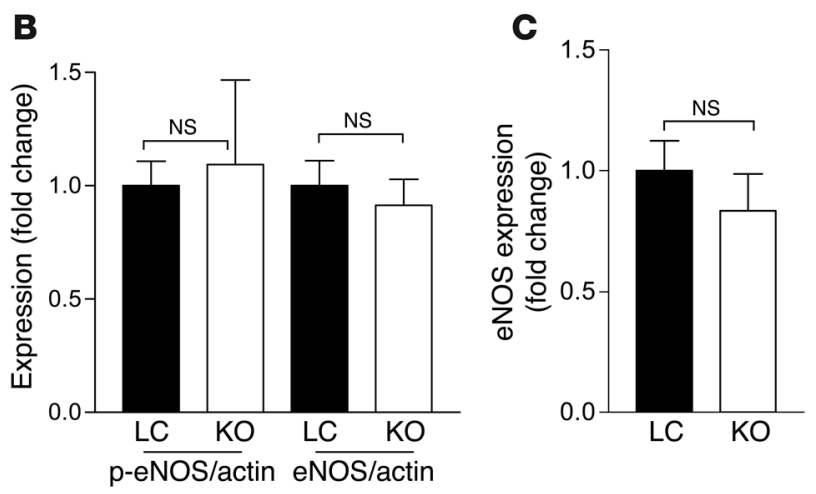

GTT and ITT. GTT and ITT were performed in 6-month-old MOREPGKO and LC mice $(n=8-11$ for separate male and female groups of each genotype) as previously described $(18,49-51)$, with the following modifications. For GTT, mice were fasted overnight for 14 hours, and glucose ( $2 \mathrm{~g} / \mathrm{kg}$ body weight) was injected intraperitoneally. Blood glucose was measured by tail bleeding using Elite glucometer (Bayer) at $0,15,30,60$, and 120 minutes after glucose injection. Tail blood $(50 \mu \mathrm{l})$ was collected at 0,30 , and 120 minutes after glucose injection for insulin measurements. For ITT, randomly fed mice at 7-9 hours into the light cycle were injected with insulin (1 IU / kg body weight; Eli Lilly and Co.) intraperitoneally, and blood glucose was measured as for GTT. Tail blood $(100 \mu \mathrm{l})$ was collected at the time of injection for blood profile analyses.

Blood profile. Plasma insulin and leptin were measured with ELISA kits from Crystal Chem. Plasma adiponectin was measured with ELISA kit from Linco. Plasma NEFAs and triglycerides and were assayed using commercial kits (Wako). Plasma aldosterone was measured by a RIA kit from Diagnostic Products Corporation as described previously $(32,33)$. PRA was measured by indirect RIA kit (DiaSorin) as the generation of Ang I per $\mu \mathrm{l}$ of plasma per hour after addition of excess Agt (ng Ang I/ $\mu \mathrm{l} / \mathrm{h})(52,53)$.

Direct measurement of blood pressure by radiotelemetry. Blood pressure and heart rate of MORE-PGKO and LC mice as well as A-ZIP mice and their WT controls ( $n=8,4$ male and 4 female, per group; all 3-4 months old) were measured by radiotelemetry (PA-C20; Data Sciences International) as described previously (54). Briefly, the left common carotid artery was cannulated with the implant catheter, and the implant body was secured in the abdominal cavity. Data were collected for 4 weeks beginning immediately after implantation. Mean systolic blood pressure, diastolic blood pressure, and heart rate were obtained by averaging the data of the final 2 weeks. For the salt loading experiment, 3-month-old male MORE-PGKO

\section{Figure 11}

Elevated plasma aldosterone level and PRA, but unchanged RAS gene expression, in MORE-PGKO mice. $n=8,4$ males and 4 females, for each genotype. (A and B) Plasma aldosterone level (A) and PRA (B) were measured by RIA as described in Methods. Results were similar in both genders and were combined. (C-E) Quantitative RT-PCR of renin (C) and Agt (D and E) expression in kidney (C), liver $(D)$, and periuterine fat (E). Only female mice were used in D. $\beta$-Actin was used as an endogenous control.

\section{Figure 10}

No significant change in eNOS expression in aortas of MOREPGKO mice. (A) Representative Western blots of phosphorylated eNOS ( $p$-eNOS) and total eNOS in aortas from male MORE-PGKO and LC mice. Actin was used as a loading control. (B) Quantification of phosphorylated eNOS and eNOS expression relative to actin. $n=4$ per group. (C) Quantitative RT-PCR of eNOS expression in male MORE-PGKO and LC mouse aortas. $\beta$-Actin was used as an endogenous control. Results were similar for female MOREPGKO and LC mice.

and LC mice ( $n=5$ per group) were implanted with radiotelemetry devices and allowed to recover for 1 week. Animals were fed normal diet $(0.7 \% \mathrm{NaCl})$ for 3 weeks, followed by a high-salt diet $(8 \% \mathrm{NaCl}$; Harlan Teklad) for another 3 weeks. Data collected during the final 2 weeks of normal diet and high-salt diet were used for analyses. Mice were kept on a 12-hour light/12-hour dark cycle.

Vasoactivity study. Rings ( $2 \mathrm{~mm}$ long) of thoracic aorta from 3- to 4month-old MORE-PGKO and LC mice $(n=4$ males and 4 females of each genotype) were mounted in a myograph system (Danish MyoTechnology $\mathrm{A} / \mathrm{S}$ ) and contracted with $\mathrm{KCl}(55)$. Phenylephrine dose-response curves were then performed, and the results were expressed as contraction percentage of maximum response to $\mathrm{KCl}$. Acetylcholine dose-response curves were performed after the aortic rings were first contracted with phenylephrine, and the results were expressed as percentage of the maximum response to acetylcholine.

Western blot analysis. Total protein was isolated from aortas, subjected to electrophoresis, and transferred to PVDF membranes as described previously $(37,56)$. Membranes were incubated with primary antibodies recognizing phosphorylated eNOS (Ser1177; Cell Signaling Technology), total eNOS (ABR-Affinity BioReagents), and actin (Santa Cruz Biotechnology Inc.). The membranes were then incubated in secondary antiserums conjugated with horseradish peroxidase and detected as previously described (56).

Statistics. Mean \pm SEM values were analyzed using Prism (version 3; GraphPad Software). Statistical comparisons between groups were performed by Student's $t$ test unless all values in a group equaled 0 , in which case Fisher's exact test was used. Curves were compared by 2 -way
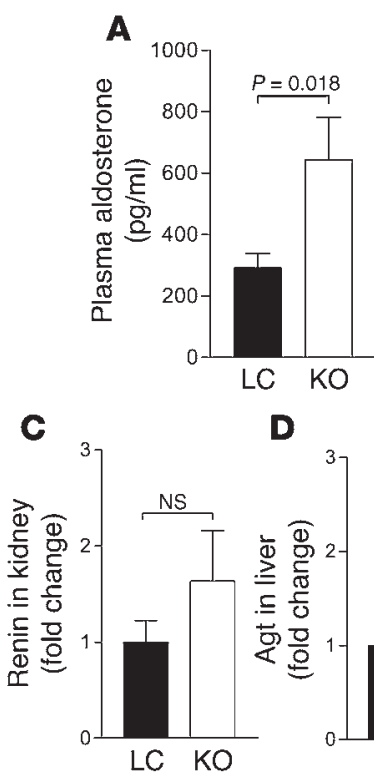

D
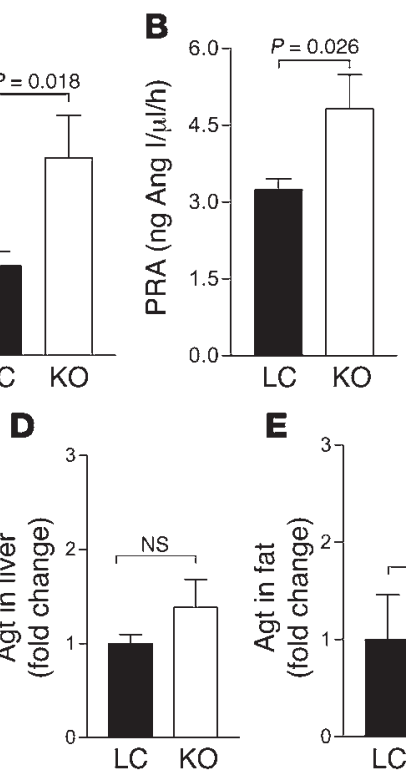

트

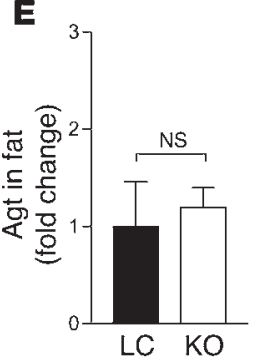


A

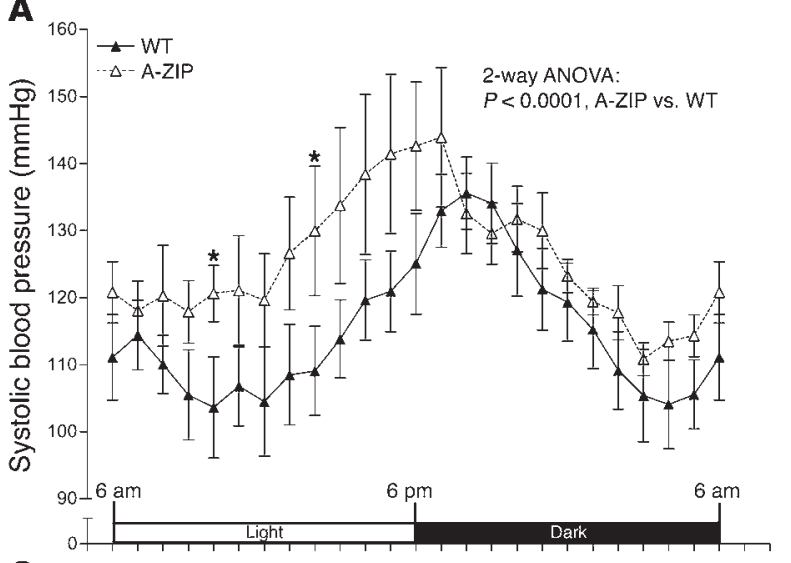

C

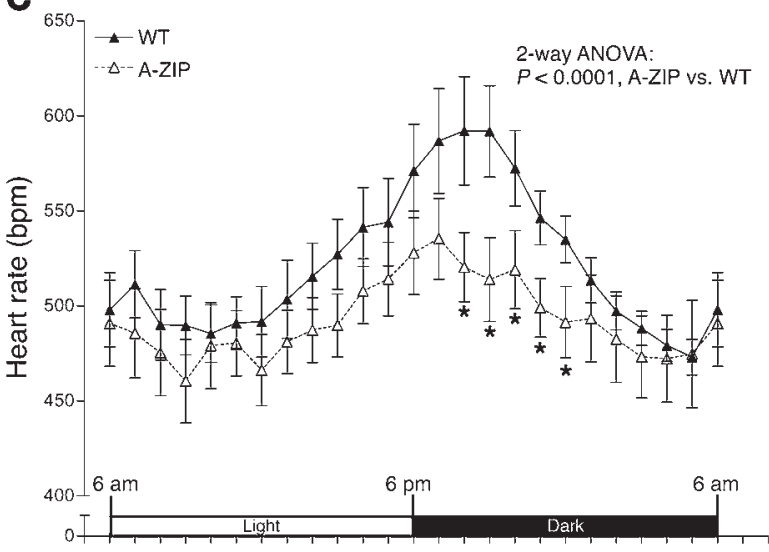

B

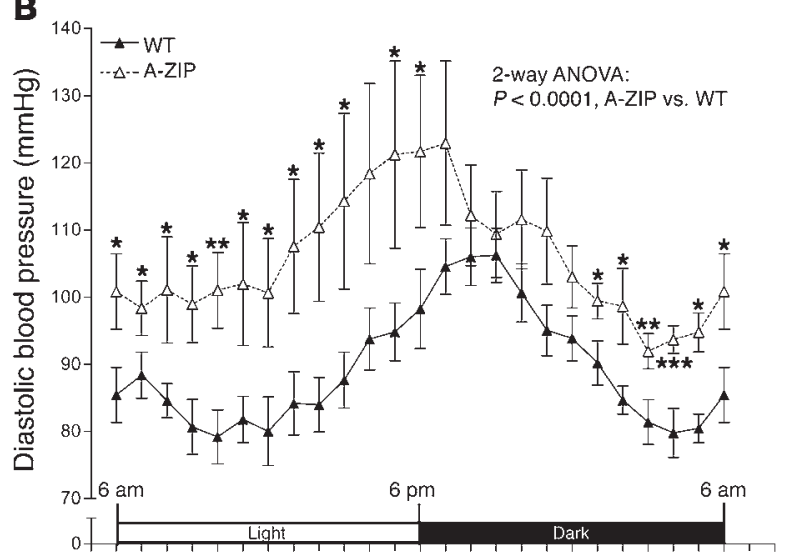

\section{Figure 12}

Hypertension in A-ZIP lipodystrophic mice. Systolic (A) and diastolic (B) blood pressure and heart rate (C) of WT and A-ZIP mice. A-ZIP mice showed significantly higher systolic and diastolic blood pressure and lower heart rates than did WT mice. Results were similar in both genders and were combined ( $n=8,4$ males and 4 females, for each genotype). Data collected over 2 weeks were averaged and presented as light/dark cycle over a 24 -hour period. ${ }^{*} P<0.05,{ }^{* *} P<0.01,{ }^{* *} P<0.001$ versus WT, Bonferroni post-test.

ANOVA and Bonferroni post-tests. Groups were considered significantly different if $P$ values were $\leq 0.05$.

\section{Acknowledgments}

This work was funded by a pilot project and cores of the Michigan Diabetes Research and Training Center (NIH5P60 DK20572 from the National Institute of Diabetes and Digestive and Kidney Diseases, NIH) and by grants R01HL083201 from the National Heart, Lung, and Blood Institute, NIH (to R.M. Mortensen), and R01HD040895 from the National Institute of Child Health and Human Development, NIH (D.S. Milstone). We thank George Stavrakis for advice and for performing immunohistochemical analysis of macrophages in murine aortas.
Received for publication April 19, 2006, and accepted in revised form December 19, 2006.

Address correspondence to: Richard M. Mortensen, Department of Molecular and Integrative Physiology, University of Michigan Medical School, 7726 Med. Sci. II, 1150 W. Medical Center Drive, Ann Arbor, Michigan 48109, USA. Phone: (734) 763-2021; Fax: (734) 936-8813; E-mail: rmort@umich.edu. Or to: David S. Milstone, Vascular Research Division, Department of Pathology, Brigham and Women's Hospital, Harvard Medical School, HNRB 730G, 77 Avenue Louis Pasteur, Boston, Massachusetts 02115, USA. Phone: (617) 525-4308; Fax: (617) 525-4331; E-mail: milstone@rascal.med.harvard.edu.

\footnotetext{
1. Evans, R.M., Barish, G.D., and Wang, Y.X. 2004 PPARs and the complex journey to obesity. Nat. Med. 10:355-361.

2. Shulman, A.I., and Mangelsdorf, D.J. 2005. Retinoid $\mathrm{x}$ receptor heterodimers in the metabolic syndrome. N. Engl. J. Med. 353:604-615.

3. Berger, J.P., Akiyama, T.E., and Meinke, P.T. 2005. PPARs: therapeutic targets for metabolic disease. Trends Pharmacol. Sci. 26:244-251.

4. Tontonoz, P., Hu, E., and Spiegelman, B.M. 1994. Stimulation of adipogenesis in fibroblasts by PPAR gamma 2, a lipid-activated transcription factor.
}

Cell. 79:1147-1156

5. Tontonoz, P., Hu, E., Graves, R.A., Budavari, A.I., and Spiegelman, B.M. 1994. mPPAR gamma 2: tissue-specific regulator of an adipocyte enhancer. Genes Dev. 8:1224-1234.

6. Rosen, E.D., et al. 1999. PPAR gamma is required for the differentiation of adipose tissue in vivo and in vitro. Mol. Cell. 4:611-617.

7. Kubota, N., et al. 1999. PPAR gamma mediates high-fat diet-induced adipocyte hypertrophy and insulin resistance. Mol. Cell. 4:597-609.

8. Barak, Y., et al. 1999. PPAR gamma is required for placental, cardiac, and adipose tissue development. Mol. Cell. 4:585-595.

9. Martens, F.M., Visseren, F.L., Lemay, J., de Koning, E.J., and Rabelink, T.J. 2002. Metabolic and additional vascular effects of thiazolidinediones. Drugs. 62:1463-1480.

10. Barroso, I., et al. 1999. Dominant negative mutations in human PPARgamma associated with severe insulin resistance, diabetes mellitus and hypertension. Nature. 402:880-883.

11. Tsai, Y.S., et al. 2004. Hypertension and abnormal fat distribution but not insulin resistance in mice 
with P465L PPAR $\gamma$. J. Clin. Invest. 114:240-249. doi:10.1172/JCI200420964.

12. Meirhaeghe, A., and Amouyel, P. 2004. Impact of genetic variation of PPARgamma in humans. Mol. Genet. Metab. 83:93-102.

13. Koutnikova, H., et al. 2003. Compensation by the muscle limits the metabolic consequences of lipodystrophy in PPAR gamma hypomorphic mice. Proc. Natl. Acad. Sci. U. S. A. 100:14457-14462.

14. Jones, J.R., et al. 2005. Deletion of PPARgamma in adipose tissues of mice protects against high fat diet-induced obesity and insulin resistance. Proc. Natl. Acad. Sci. U. S. A. 102:6207-6212.

15. He, W., et al. 2003. Adipose-specific peroxisome proliferator-activated receptor gamma knockout causes insulin resistance in fat and liver but not in muscle. Proc. Natl. Acad. Sci. U. S. A. 100:15712-15717.

16. Imai, T., et al. 2004. Peroxisome proliferator-activated receptor gamma is required in mature white and brown adipocytes for their survival in the mouse. Proc. Natl. Acad. Sci. U. S. A. 101:4543-4547.

17. Hevener, A.L., et al. 2003. Muscle-specific Pparg deletion causes insulin resistance. Nat. Med. 9:1491-1497

18. Norris, A.W., et al. 2003. Muscle-specific PPAR $\gamma$ deficient mice develop increased adiposity and insulin resistance but respond to thiazolidinediones. J. Clin. Invest. 112:608-618. doi:10.1172/ JCI200317305.

19. Matsusue, K., et al. 2003. Liver-specific disruption of PPAR $\gamma$ in leptin-deficient mice improves fatty liver but aggravates diabetic phenotypes. J. Clin. Invest. 111:737-747. doi:10.1172/JCI200317223.

20. Gavrilova, O., et al. 2003. Liver peroxisome proliferator-activated receptor gamma contributes to hepatic steatosis, triglyceride clearance, and regulation of body fat mass. J. Biol. Chem. 278:34268-34276

21. Nicol, C.J., Adachi, M., Akiyama, T.E., and Gonzalez, F.J. 2005. PPARgamma in endothelial cells influences high fat diet-induced hypertension. Am. J. Hypertens. 18:549-556.

22. Zhang, J., et al. 2004. Selective disruption of PPARgamma 2 impairs the development of adipose tissue and insulin sensitivity. Proc. Natl. Acad. Sci. U. S. A. 101:10703-10708.

23. Moitra, J., et al. 1998. Life without white fat: a transgenic mouse. Genes Dev. 12:3168-3181.

24. Tallquist, M.D., and Soriano, P. 2000. Epiblastrestricted Cre expression in MORE mice: a tool to distinguish embryonic vs. extra-embryonic gene function. Genesis. 26:113-115.

25. St. John Sutton, M., et al. 2002. A comparison of the effects of rosiglitazone and glyburide on cardiovascular function and glycemic control in patients with type 2 diabetes. Diabetes Care. 25:2058-2064.

26. Atkins, K.B., Northcott, C.A., Watts, S.W., and Brosius, F.C. 2005. Effects of PPAR-gamma ligands on vascular smooth muscle marker expression in hypertensive and normal arteries. Am. J. Physiol. Heart Circ. Physiol. 288:H235-H243.

27. Diep, Q.N., et al. 2002. Structure, endothelial function, cell growth, and inflammation in blood vessels of angiotensin II-infused rats: role of per- oxisome proliferator-activated receptor-gamma. Circulation. 105:2296-2302.

28. Brown, R.D., et al. 2006. Influence of the adenosine A1 receptor on blood pressure regulation and renin release. Am. J. Physiol. Regul. Integr. Comp. Physiol. 290:R1324-R1329.

29. Ohashi, Y., et al. 1998. Hypotension and reduced nitric oxide-elicited vasorelaxation in transgenic mice overexpressing endothelial nitric oxide synthase. J. Clin. Invest. 102:2061-2071.

30. Polikandriotis, J.A., Mazzella, L.J., Rupnow, H.L., and Hart, C.M. 2005. Peroxisome proliferatoractivated receptor gamma ligands stimulate endothelial nitric oxide production through distinct peroxisome proliferator-activated receptor gamma-dependent mechanisms. Arterioscler. Thromb. Vasc. Biol. 25:1810-1816.

31. Paul, M., Poyan Mehr, A., and Kreutz, R. 2006. Physiology of local renin-angiotensin systems. Physiol. Rev. 86:747-803.

32. Guan, Y., et al. 2005. Thiazolidinediones expand body fluid volume through PPARgamma stimulation of $\mathrm{ENaC}$-mediated renal salt absorption. Nat. Med. 11:861-866

33. Zhang, H., et al. 2005. Collecting duct-specific deletion of peroxisome proliferator-activated receptor gamma blocks thiazolidinedioneinduced fluid retention. Proc. Natl. Acad. Sci.U. S. A 102:9406-9411.

34. Hegele, R.A., Cao, H., Frankowski, C., Mathews, S.T., and Leff, T. 2002. PPARG F388L, a transactivationdeficient mutant, in familial partial lipodystrophy. Diabetes. 51:3586-3590.

35. Savage, D.B., et al. 2003. Human metabolic syndrome resulting from dominant-negative mutations in the nuclear receptor peroxisome proliferator-activated receptor-gamma. Diabetes. 52:910-917.

36. Dieudonne, M.N., Pecquery, R., Leneveu, M.C., and Giudicelli, Y. 2000. Opposite effects of androgens and estrogens on adipogenesis in rat preadipocytes: evidence for sex and site-related specificities and possible involvement of insulin-like growth factor 1 receptor and peroxisome proliferator-activated receptor gamma2. Endocrinology. 141:649-656.

37. Duan, S.Z., Ivashchenko, C.Y., Russell, M.W., Milstone, D.S., and Mortensen, R.M. 2005. Cardiomyocyte-specific knockout and agonist of peroxisome proliferator-activated receptor-gamma both induce cardiac hypertrophy in mice. Circ. Res. 97:372-379.

38. Rosen, E.D., et al. 2003. Targeted elimination of peroxisome proliferator-activated receptor gamma in beta cells leads to abnormalities in islet mass without compromising glucose homeostasis. Mol. Cell. Biol. 23:7222-7229.

39. Lim, S., et al. 2006. PPARgamma gene transfer sustains apoptosis, inhibits vascular smooth muscle cell proliferation, and reduces neointima formation after balloon injury in rats. Arterioscler. Thromb. Vasc. Biol. 26:808-813.

40. Ward, J.E., Gould, H., Harris, T., Bonacci, J.V., and Stewart, A.G. 2004. PPAR gamma ligands, 15-deoxydelta12,14-prostaglandin $\mathrm{J} 2$ and rosiglitazone regulate human cultured airway smooth muscle proliferation through different mechanisms. Br. J. Pharmacol. 141:517-525.

41. Marra, F., et al. 2005. Thiazolidinedione treatment inhibits bile duct proliferation and fibrosis in a rat model of chronic cholestasis. World J. Gastroenterol. 11:4931-4938.

42. Zafiriou, S., et al. 2005. Pioglitazone inhibits cell growth and reduces matrix production in human kidney fibroblasts. J. Am. Soc. Nephrol. 16:638-645.

43. Girnun, G.D., et al. 2002. APC-dependent suppression of colon carcinogenesis by PPARgamma. Proc. Natl. Acad. Sci. U. S. A. 99:13771-13776.

44. Lehrke, M., and Lazar, M.A. 2005. The many faces of PPARgamma. Cell. 123:993-999.

45. Lee, C.H., et al. 2003. Transcriptional repression of atherogenic inflammation: modulation by PPARdelta. Science. 302:453-457.

46. Haynes, W.G. 2000. Interaction between leptin and sympathetic nervous system in hypertension. Curr. Hypertens. Rep. 2:311-318.

47. Akiyama, T.E., et al. 2002. Conditional disruption of the peroxisome proliferator-activated receptor gamma gene in mice results in lowered expression of ABCA1, ABCG1, and apoE in macrophages and reduced cholesterol efflux. Mol. Cell. Biol. 22:2607-2619.

48. Schoenfeld, J.R., et al. 1998. Distinct molecular phenotypes in murine cardiac muscle development, growth, and hypertrophy. J. Mol. Cell. Cardiol. 30:2269-2280.

49. Bottner, A., et al. 2000. Increased body fat mass and suppression of circulating leptin levels in response to hypersecretion of epinephrine in phenylethanolamine-N-methyltransferase (PNMT)-overexpressing mice. Endocrinology. 141:4239-4246.

50. Loftus, T.M., Kuhajda, F.P., and Lane, M.D. 1998. Insulin depletion leads to adipose-specific cell death in obese but not lean mice. Proc. Natl. Acad. Sci. U. S. A. 95:14168-14172.

51. Tsao, T.S., et al. 1997. Muscle-specific transgenic complementation of GLUT4-deficient mice. Effects on glucose but not lipid metabolism. J. Clin. Invest. 100:671-677.

52. Kim, S.M., Mizel, D., Huang, Y.G., Briggs, J.P., and Schnermann,J.2006. Adenosine as a mediator of macula densa-dependent inhibition of renin secretion. Am. J. Physiol. Renal Physiol. 290:F1016-F1023.

53. Ahn, D., et al. 2004. Collecting duct-specific knockout of endothelin-1 causes hypertension and sodium retention. J. Clin. Invest. 114:504-511. doi:10.1172/JCI200421064.

54. Whitesall, S.E., Hoff, J.B., Vollmer, A.P., and D'Alecy, L.G. 2004. Comparison of simultaneous measurement of mouse systolic arterial blood pressure by radiotelemetry and tail-cuff methods. Am. J. Physiol. Heart Circ. Physiol. 286:H2408-H2415.

55. Park, J.L., et al. 2005. GLUT4 facilitative glucose transporter specifically and differentially contributes to agonist-induced vascular reactivity in mouse aorta. Arterioscler. Thromb. Vasc. Biol. 25:1596-1602.

56. Sowell, M.O., et al. 1997. Targeted inactivation of alphai 2 or alphai3 disrupts activation of the cardiac muscarinic $\mathrm{K}+$ channel, $\mathrm{IK}+\mathrm{Ach}$, in intact cells. Proc. Natl. Acad. Sci. U. S. A. 94:7921-7926. 